\title{
LITERATURA EN AMÉRICA LATINA: LA HISTORIA NO ESCRITA
}

\author{
Juan-Manuel García Ramos \\ Universidad de La Laguna
}

\section{Resumen}

Los nuevos espacios de la creación literaria ya no están confinados en los estados-nación o en las naciones-estado, ni en el deseable subcontinente federalizado sońado por Bolívar, sino que se inscriben en los marcos imprecisos de la cultura pop, del ciberespacio, la blogosfera, la mentalidad abierta de las grandes migraciones. La historia, como vemos, ya es otra. La literatura, en consecuencia, también.

Palabras Clave: Literatura sustituta de la Historia, nuevo diálogo entre la Literatura de América Latina y Estados Unidos, nacionalismos literarios y globalización.

\section{Abstract}

The new spaces of literary creation are no longer confined to the nation-states or to the states-nation, nor in the desirable federal subcontinent dreamt by Bolívar, but rather fall within the vague frames of the pop culture, the cyberspace, the blogosphere and the open mentality of great migrations. The History, as we can see, is different, and as a consequence, the literature too.

Key Words: Literature substitute of History, new dialogue between Latin-American and American literature, literary nationalisms and globalisation.

Parto de una reflexión que tomo prestada de José Miguel Oviedo (1997: 73): «En América Latina, la Historia ha sido, desde los cronistas coloniales, una preocupación mayor de su literatura». Y continúo con Oviedo, sosteniendo que la literatura de América Latina ha tenido que enfrentar la responsabilidad de corregir a una historia la mayoría de las veces falsificada, cuando no tergiversada o silenciada.

En la clásica distinción aristotélica entre literatura (poesía) e historia, entre lo que pudo o debió suceder, y lo que realmente sucedió, cabe, en el ámbito de la América a la que nos referimos, una tercera posibilidad: la literatura que sustituye y corrige a la historia cuando esta miente o se escabulle de sus tareas canónicas.

Quizá el problema se agrava más en esa América porque no solo rivalizan las construcciones de la literatura y de la historiografía académica o extraacadémica, 
sino que a ellas se añade el uso ventajista del pasado que hace la política, tal y como hoy podemos comprobar con un ejemplo tan diáfano como el de la figura de Simón Bolívar: ¿nos quedamos con el Bolívar recreado por García Márquez en su El general en su laberinto - esa novela inspirada en un cuento de Álvaro Mutis: «El último rostro»-, con el Bolívar asumido convencionalmente por la memoria colectiva, o con el Bolívar gestionado por Hugo Chávez en su república de nuevo cuño? ¿De cuántos Bolívar disponemos?

Como diría Claudio Magris (2001: 23), solo la literatura ordena lo que antes nos quisieron decir la historia —al contar, bien o mal, los hechos-, la sociología —al describir los procesos_, la estadística —al proporcionar las cifras-, o la política —al conjugar todas esas informaciones en su propio beneficio-. Según el narrador y profesor triestino, sabemos lo que fue la Francia de la Restauración y lo que es la metrópoli contemporánea gracias a las novelas de Balzac, que nos acercan a lo amado, deseado o falseado por los hombres de esa época, y a novelas como Berlín Alexanderplatz, de Alfred Döblin, donde la vida urbana se presenta en toda su complejidad y alienación.

Si la historia nos abre el vastísimo horizonte de la humanidad en todas sus dimensiones, nunca podrá prescindir de las interpretaciones de la literatura. ¿Qué obra nos proporciona con mayor nitidez la imagen de la España de los siglos XVI y XVII que el Quijote o la gran poesía satírica de Quevedo? ¿Quién es hoy más real, el soldado español manco del siglo XviI, autor de esa novela fundacional, o su tierno hidalgo? ¿Qué obra nos proporciona con mayor amplitud y riqueza la historia de la América Hispana en su conjunto que Cien años de soledad?

Lo que sucede con la literatura de América Latina es que casi siempre luchó contra la historia para enmendarla y para facilitar a los habitantes de esa región del mundo una versión más apacible, también más completa, de lo sucedido. En ese sentido, nos parece un acierto la breve y lúcida reseña que el mexicano Jorge Volpi ha hecho de Cien años de soledad para el especial «Babelia» del diario madrileño El País (28-112009) con motivo del Bicentenario de la independencia americana. Dice allí Volpi:

Imaginemos una América Latina sin Cien años de soledad. Su autor, un brioso periodista de izquierdas, apenas conocido [...] jamás concluye su novela. [...] En este escenario, tal vez el boom hubiese existido, pero el realismo mágico habría perdido su carácter de espejo único de América Latina. Dictadores y rebeldes hubiesen sido retratados con crudeza, sin delirios sobrenaturales. Los pobladores de esta región no nos habríamos convertido en apáticos testigos de las prodigiosas calamidades que nos azotan. Y nuestra historia no hubiese sido leída como una intrincada saga familiar. En resumen: sin esta novela, el mundo habría percibido una América Latina más real, pero infinitamente más triste y anodina.

Si nos fijamos bien, en esas páginas de García Márquez, tan ponderadas por Volpi, se nos da cuenta de lo que significó la utopía del Descubrimiento de América, la Conquista, la Colonia, la Independencia, las dictaduras posteriores, la neocolonización estadounidense... La columna vertebral de la crónica de la familia Buendía ha sido capaz de humanizar una historia que, como sostenía José Miguel Oviedo, se negó siempre a ser contada con la seriedad y el rigor requeridos. 
Pero, ¿solo existe la literatura para volver más digerible la historia? ¿Operó de ese modo la literatura en América Latina en todos los tiempos?

Toda la literatura que se escribe en América Latina en el siglo XIX es un intento de inventariar una realidad que se escapa a la inteligencia de los habitantes de ese subcontinente. También es un intento de erguir identidades muchas veces inexistentes, y de justificar entes políticos nacidos por generación espontánea ${ }^{1}$.

Por seguir con la figura de Bolívar, es constatable, en los primeros textos generados por el Libertador, su ignorancia de la realidad física y social que pretendía emancipar del imperio espańol. Sin ir más lejos, en su "Carta de Jamaica", firmada en Kingston el 6 de septiembre de 1815 y dirigida a un súbdito británico (supuestamente Henry Cullen, residenciado en Falmouth, cerca de Montego Bay, en la costa norte jamaicana, aunque, en realidad, esa carta iba dirigida a Inglaterra, para pedirle ayuda en el proceso de independencia americana), Bolívar (1981: 148) reconoce la precariedad de su información sobre el vasto territorio que se propone liberar: «Así, me encuentro en un conflicto, entre el deseo de corresponder a la confianza con que $\mathrm{Vd}$. me favorece y el impedimento de satisfacerla, tanto por la falta de documentos y libros, cuanto por los limitados conocimientos que poseo de un país tan inmenso, variado y desconocido, como el Nuevo Mundo».

Esa honrada inseguridad de Bolívar a la hora de referirse, a principios del siglo XIX, a la América en proceso de emancipación nos la volvemos a encontrar al final de esa misma centuria en otro intelectual y guerrero como fue José Martí. En su tan citado ensayo "Nuestra América», publicado por primera vez en La Revista Ilustrada de Nueva York el 1 de enero de 1891, el líder de la independencia cubana (Martí, 1995: 120) sigue insistiendo en la necesidad de descubrir América a los americanos de su tiempo: «En el periódico, en la cátedra, en la academia, debe llevarse adelante el estudio de los factores reales del país. Conocerlos basta, sin vendas ni ambages, porque el que pone de lado, por voluntad $\mathrm{u}$ olvido, una parte de la verdad, cae a la larga por la verdad que le faltó, que crece en la negligencia y derriba lo que se levanta sin ella».

Bolívar y Martí abren y cierran el siglo XIX con declaraciones sinceras sobre los territorios y las sociedades por las que luchan. Tanto uno como otro insisten en el empeño de conocer en profundidad geografías, etnias y maneras de ser y de enfrentar el mundo de sus compatriotas, un material del que no disponen ni en 1815 ni en 1891, fechas de publicación de sus alegatos e inventarios respectivos de

1 «La confusión americana creó estas realidades imaginadas: Estados nacionales, instituciones republicanas, ciudadanías comunes, soberanía popular, banderas e himnos nacionales, etc., así como la liquidación de sus opuestos conceptuales: Imperios dinásticos, instituciones monárquicas, absolutismos, sometimientos, noblezas heredadas, servidumbre, ghettos, etc.». En Benedict Anderson (1993): Comunidades imaginadas. Reflexiones sobre el origen y la difusión del nacionalismo, traducción de Eduardo L. Suárez, México, FCE, 4. ${ }^{a}$ reimp., p. 121.

En este mismo sentido, también ha de consultarse la obra Escribiendo la Independencia. Perspectivas postcoloniales sobre la literatura hispanoamericana del siglo XIX, Madrid, Iberoamericana Vervuert, 2010, cuyo título ya nos informa de lo perseguido por sus autores. 
sus limitados conocimientos del mundo al que pertenecen en distintas etapas del devenir histórico de esos pueblos.

Pero, tanto Bolívar como Martí, defienden una idea de conjunto de la América Hispana y de sus agregados, portugueses, franceses, ingleses y holandeses. El germen del concepto de América Latina ya está en ellos y el transcurrir de la historia no hará sino darles la razón.

En la literatura, Andrés Bello propondrá también una poética de conjunto, una invitación a redescubrir para la nueva palabra emancipada una nueva realidad geográfica e histórica. Postula todo ello en la primera parte de su «Alocución a la poesía», lo prosigue en su otra silva, "A la agricultura de la zona tórrida», y quizá lo redondea con su divulgada Gramática, todo un programa de acción y de intervención intelectual que se correspondía con las ideas federalistas del Libertador por excelencia. Pero acechaba la fragmentación. La fragmentación literaria se puso al servicio de la previa fragmentación política, y las ideas nacionalistas — contenidas en la obra Fragmentos sobre la literatura alemana moderna, 1766-1767- de un prerromántico alemán como Johann Gottfried Herder, quien acuñó el término Nacionalismus ${ }^{2}$, se adentraron con suma facilidad en el puzle de repúblicas resultante del fracaso de la América unida soñada por Bolívar.

Muy pronto, instrumentos intelectuales de esa inesperada independencia se ponen a trabajar en el diseño de las nuevas literaturas nacionales. En 1836 se funda la Academia de Letrán en México; en 1837 el Salón Literario Marcos Sastre, en Buenos Aires; en 1842, la Sociedad Literaria en Santiago de Chile. Todas esas corporaciones propugnan el cantonalismo literario y se aprestan a recomendar a sus creadores la recuperación de los rasgos que caractericen las letras de esos nuevos países frente a cualesquiera otros, de dentro o de fuera de América. Por seguir con Herder, recordemos algunas de sus propuestas, tan seguidas al pie de la letra por las nuevas naciones de la América liberada en el siglo XIx: «Un poeta es el creador de un pueblo, le ofrece un mundo para que lo contemple, y sostiene el alma del pueblo en la palma de su mano» ${ }^{3}$.

Esfuerzos literarios abarcadores de las primeras décadas de la Independencia, como los liderados por Andrés Bello y continuados por un José Joaquín de Olmedo o un José María Heredia, fueron sustituidos gradualmente, a medida que se conformaban los nuevos pueblos producto del desgajamiento de los antiguos virreinatos y los enfrentamientos de los caudillos de las guerras de liberación ${ }^{4}$, por esfuerzos literarios centrados en levantar acta identitaria de las nuevas realidades nacionales. La mirada panorámica generosa se convertía en la mirada local e interesada. A esa

2 Cfr.: Berlin, Isaiah (2000): Vico y Herder. Dos estudios en la historia de las ideas, edición de Henry Hardy y traducción de Carmen González del Tejo, Madrid, Cátedra, p. 232.

${ }_{3}^{3}$ Ibídem, p. 257.

${ }^{4}$ En una de las conversaciones entre Simón Bolívar y Antonio José de Sucre, recreadas por Gabriel García Márquez (1989) en su El general en su laberinto, el «Gran Mariscal de Ayacucho» le dice estas palabras al Libertador: «Tal parece como si hubiéramos sembrado tan hondo el ideal de la independencia, que estos pueblos están tratando ahora de independizarse los unos de los otros». En la edición de Madrid, Mondadori, p. 26. 
tarea se dedicaron desde Esteban Echeverría, Domingo Faustino Sarmiento, José Mármol, o la poesía gauchesca en general, en Argentina, hasta Alberto Blest Gana en Chile, Jorge Isaacs en Colombia, Juan León Mera en Ecuador, Cirilo Villaverde o Gertrudis Gómez de Avellaneda en Cuba, o Clorinda Matto de Turner en Perú.

Se trataba de definir, desde la literatura y desde distintas intensidades genéricas y creativas, las almas ocultas de esos países recién nacidos, aunque algunos de ellos ya contaban con una jerarquización de sus pasados más definida, como era el caso de Argentina o el caso de México, referencias de los viejos virreinatos del Río de la Plata y de Nueva Espańa.

Por lo tanto, la historia se troceó y se contrajo, y la literatura la acompañó en esas preocupaciones y en ese cierre de zoom con el fin de alcanzar objetivos menos ambiciosos. Pero todos esos autores se impusieron recomponer las crónicas mediatas e inmediatas de sus pueblos, la literatura era la guía para la revelación de esas nuevas realidades convertidas en estados independientes. Asuntos como la esclavitud, indagada por Villaverde o Gómez de Avellaneda, la situación de las poblaciones indígenas, en el caso de Matto de Turner, la civilización y la barbarie, en sus distintas modalidades, tratadas por Sarmiento o José Hernández, algo menos por Echeverría; las luchas políticas en Chile o en Argentina, colocadas como fondo de sus novelas, en los casos de Blest Gana o Mármol, o el mundo telúrico ecuatoriano, en el caso de León Mera, son algunos ejemplos de cómo la literatura se dispuso a gestionar, desde su legislación verbal específica, los pasados de esos pueblos que, como decía Antonio José de Sucre a través de la imaginación de Gabriel García Márquez, estaban «tratando ahora de independizarse los unos de los otros».

En general, la narrativa latinoamericana continuó con esas ocupaciones y preocupaciones en las primeras décadas del siglo xx por medio de las vías nativistas, historicistas e indigenistas que jalonaron ese periodo, hasta desembocar, como bien subrayó en su momento Ángel Rama (Díaz Caballero, 1997: 325-348), en lo que vienen a significar en 1938 relatos como «Tlön, Uqbar, Orbis Tertius», de Jorge Luis Borges, o novelas como El pozo, publicada por Juan Carlos Onetti en 1939, como modelos paradigmáticos de narraciones aliviadas de las viejas responsabilidades de caracterizar un tiempo y un espacio concretos, una "patria», y como insoslayables antecedentes de lo que esa narrativa de la América a la que nos referimos iba a plantear a partir de la década de los sesenta.

En poesía, la historia es otra, si se nos permite cierta simplificación del problema. Tanto Ángel Rama, como Octavio Paz en su día, coincidieron en fijar como fecha de inicio de la verdadera autonomía literaria latinoamericana los años de vigencia del movimiento modernista liderado por Rubén Darío, años que van desde 1880 hasta 1920, aproximadamente. Ángel Rama (Rojo, 2008: 95), con su descaro crítico, quiso defender además en dos de sus libros póstumos, Rubén Dario y el modernismo (1985) y Las máscaras democráticas del modernismo (también de 1985), no solo la «impregnación americana» del modernismo rubeniano, sino su origen "popular», combatiendo el afrancesamiento y el elitismo asignados por la crítica hasta ese momento a dicho movimiento literario.

Esa autonomía literaria de la poesía modernista y postmodernista tendrá una continuación ya imparable en lo que supondrían las lindantes vanguardias y las 
postvanguardias en América Latina, hasta llegar a la postmodernidad de nuestros días, al derrumbe de tantos absolutos estéticos y éticos, aunque en medio de todos esos procesos encabalgados todavía se den apariciones tan al margen como la que supuso el Canto General, del siempre controvertido Neruda, que venía a remedar muchos años después la receta literaria de Andrés Bello en sus empeños de cartografiar la geografía y la historia de la América meridional, un esfuerzo de épica continental tan anacrónico como deslumbrante y que hizo reconocer a Carlos Fuentes una influencia que tiene mucho que ver con lo señalado en el mismo título de esta ponencia. Fuentes (2004, p. 6) ha aceptado sin ambages que las novelas de su generación de los años sesenta del siglo xx se escribieron todas bajo el signo de Neruda, porque el autor de Canto General les enseñó a sus coetáneos a prestarles voz literaria a los silencios de la historia. "Neruda nos dijo a todos: si no salvamos nuestro pasado y lo hacemos vivir en el presente, no tendremos futuro alguno».

Al margen de las calidades poéticas del Canto General de Pablo Neruda y de las posibles influencias ejercidas en la generación de Carlos Fuentes, en lo que sí podemos estar de acuerdo es en la recuperación de las ideas políticas y literarias de Simón Bolívar y de Andrés Bello, respectivamente, por parte de los narradores que empiezan a darse a conocer en América Latina en torno a la década de los sesenta y a pronunciarse a través de una voz "continental», por encima y por debajo de todas las estéticas literarias que se han sucedido desde principios del siglo Xx.

En torno a los ańos sesenta de esa centuria, los nacionalismos literarios se han atemperado tanto en la poesía como en la narrativa, pero la responsabilidad de apelar a una historia silenciada o tergiversada permanece en muchos de esos escritores. Lo acepta el mismo Fuentes, pero otro tanto podría decir Alejo Carpentier, Juan Rulfo, Mario Vargas Llosa, Gabriel García Márquez. Y en este último sentido, no estamos hablando, que quede claro, del subgénero de la vieja (vgr.: Jicoténcal, 1826, de autor anónimo hasta hoy, a pesar de las atribuciones hechas al respecto) o nueva (vgr.: Los perros del paraíso, 1983, de Abel Posse) novela histórica que toma su formato del Romanticismo, sino de una tendencia generalizada de la literatura narrativa en general, como ha insistido José Emilio Pacheco5: «La novela [latinoamericana] ha sido desde sus orígenes la privatización de la historia [...], historia de la vida privada, historia de la gente que no tiene historia [...]. En este sentido todas las novelas son novelas históricas».

Pareciera que, a pesar de los avances formales exigidos por la evolución y la reformulación de lo literario, las deudas de la literatura de América Latina con la historia siguen pendientes para muchos de sus creadores. ¿Una dependencia crónica nacida en el siglo de la Emancipación? ¿Acaso generada desde la Colonia?

Quizá tengamos que volver a las afirmaciones de José Miguel Oviedo y aceptar que la corrección de la historia de América Latina sigue siendo una labor de la literatura de esa región, una literatura que ha llegado a superar los ensimismamientos

Cito por Seymour Menton (1993), La nueva novela histórica de la América Latina, 19791992, México, Fondo de Cultura Económica, p. 32. 
emanados de corrientes poéticas y narrativas que animaban a desprenderse de esas viejas responsabilidades. ¿ No ha llegado a influir esa constante literaturización de la historia en la escritura de la propia historia, como podría ser el caso de un libro como Las venas abiertas de América Latina o las mismas reelaboraciones de las crónicas llevadas a cabo por Eduardo Galeano?

La literatura de América Latina se resiste a dejar de mirar a la historia — lo histórico es el magma sobre el que opera la literatura - para entregarse solo al uso de la imaginación; los escritores parten de la responsabilidad de volver sobre lo ya dicho, lo aparentemente dado por bueno, para revisarlo, enmendarlo, refundarlo, transformarlo. ¿¿Ridiculizarlo?, ¿transcenderlo?

Para convertirlo en algo más inquietante, para mantener la memoria en continua alerta. Todo puede ser visto de nuevo desde otra perspectiva: los viajes de Colón - Benítez Rojo, Abel Posse, Carpentier, Roa Bastos, Homero Aridjis, Herminio Martínez-, la llegada de la Revolución Francesa al Caribe —Carpentier, por extenso-, el viaje científico de Humboldt —Denzil Romero-, las guerras de la independencia del cono sur —el mismo Borges, en sus cuentos, en sus poemas-, el mundo mitológico del gaucho — caricaturizado por la prosa corrosiva de Roberto Bolaño—, la encrucijada revolucionaria mexicana - Octavio Paz, Carlos Fuentes—, el trienio imperial de Maximiliano y Carlota en México - Fernando del Paso-.

La literatura no cesa en esas operaciones de relectura, de reinvención, de desconfianza con lo ya apalabrado. Se diría que reta sin cuartel a la historia de la que se nutre, rivaliza con sus fundamentos y la obliga a contenerse, a corregirse, a desacralizarse.

Lo dijo Octavio Paz (1986, p. 207) antes de despedirse de nosotros: «Este fin de siglo ha sido también una vuelta de los tiempos; descubrimos ahora lo que los antiguos sabían: la historia es una presencia en blanco, un rostro desierto. El poeta y el novelista deben devolver a ese rostro sus rasgos humanos. Es una empresa que requiere imaginación pero, asimismo, temple moral. La literatura que escribimos no renuncia a la historia pero sí a las simplificaciones del arte ideológico y a las afirmaciones y negaciones perentorias de los modernistas. No es un arte de certidumbres sino de exploración, no es una poesía que muestra un camino sino que lo busca».

La interrogación permanente como metodología de trabajo literario: en esas está Octavio Paz, quien además nos advierte de que en América Latina el ocaso de las vanguardias históricas se fusiona con las decepciones y los descréditos de las ideologías políticas, acaso para desembocar en los nuevos escepticismos que representan movimientos como los protagonizados por los latinounidenses, término acuñado por la profesora y crítica cubana Eliana Rivero para referirse a los escritores latinoamericanos que producen su obra en Estados Unidos y que empiezan a modificar no solo a la sociedad que los recibe sino a aquellas de las que proceden.

Se modifican las fronteras políticas y se modifican las fronteras espirituales como nunca hubiera podido imaginar un pensador como José Enrique Rodó en 1900, fecha de la publicación de su Ariel, tan hostil con la cultura anglosajona del norte de América.

Y esas nuevas relaciones entre la América Latina y la América que habla inglés precipitan un vuelco de los imaginarios literarios respectivos, un freno a los 
nacionalismos culturales y a los viejos recelos políticos de los bloques subcontinentales antiguamente en contienda. La historia abandona sus maniqueísmos y comienza una recolonización muy light, consentida por las partes, casi acordada. La historia es otra y obliga a la literatura a ser también otra.

Quizá los ejemplos más diáfanos de esta nueva situación se encuentren en dos antologías $^{6}$ y en un manifiesto de las nuevas generaciones narrativas latinoamericanas ${ }^{7}$.

Las antologías son las preparadas por los escritores y críticos chilenos Alberto Fuguet y Sergio Gómez: $M c O n d o$, Barcelona, Grijalbo-Mondadori, 1996; y por el mismo Fuguet y el boliviano Edmundo Paz Soldán: Se habla español. Voces latinas en USA, Miami, Alfaguara, 2000.

El manifiesto es el conocido como Manifiesto Crack $^{8}$, leído por primera vez en agosto de 1996 en Ciudad de México, durante la presentación de cinco novelas que planteaban como consigna general huir de una literatura complaciente: El temperamento melancólico, de Jorge Volpi; Memoria de los días, de Pedro Ángel Palou; Si volviesen sus majestades, de Ignacio Padilla; La conspiración idiota, de Ricardo Chávez Castañeda, y Las rémoras, de Eloy Urroz.

Estas nuevas propuestas conllevan nuevas relaciones culturales entre América Latina y Estados Unidos y han desnacionalizado y hasta descontinentalizado el discurso histórico de los pueblos americanos de habla española, y, por añadidura, su discurso literario, en complicidad abierta con la América anglosajona del norte. El crítico español Ignacio Echevarría (2010: 25), al aludir a algunas conclusiones del III Congreso de Nuevos Narradores Iberoamericanos, celebrado en Casa de América de Madrid en junio de 2010, habla de «la condición transnacional o extraterritorial de muchos de estos escritores».

Estamos ante un proceso de globalización de ambas Américas donde la cultura de la palabra rivaliza con la cultura de la imagen, del pop, del rock, del vídeo, del walkman — la sofisticada tecnología de la comunicación humana-, y, como sostiene el ensayista cubano Jorge Fornet (2007), en un luminoso trabajo sobre la existencia o inexistencia de una literatura latinoamericana, los escritores que se alinean

${ }^{6}$ Habría una tercera antología, ridiculizadora de estas dos principales: la que propuso en 1996 el narrador chileno Roberto Bolaño en su formato de «diccionario de autores infames»: La literatura nazi en América, una de las parodias más divertidas de la historia real de la literatura latinoamericana, pero que solo se queda en eso, en su papel corrosivo.

7 Nada distinto parece suceder en el ámbito de la última poesía latinoamericana. La antipoesía de Nicanor Parra y el concretismo brasileño de principios de los años cincuenta del siglo xx, es decir, la antivanguardia del primero de esos movimientos y el intento de reposición de la vanguardia, del segundo, constituyen «la aceptación de un ciclo poético terminado: el ciclo del lamento-por-lo-que-fue la poesía occidental y la aceptación de lo que la poesía es en ese presente histórico", tal y como ha afirmado el poeta y crítico uruguayo Eduardo Milán (2007): Pulir huesos. Veintitrés poetas latinoamericanos (19501965), Barcelona, Galaxia Gutenberg-Círculo de Lectores, pp. 13-14. La poesía que cubre las décadas finales del siglo xx y primeras del xxi parece circular, según el mismo Milán, a partir de una vocación de exploración y adopción de los márgenes que aquellos momentos poéticos radicales —la antipoesía y el concretismo- relegaron.

${ }^{8}$ Cfr.: Manifiesto Crack, Lateral. Revista de Cultura, México, núm. 70, octubre de 2000. 
en esa dirección son «post-todo: post-moderno, post-yuppie, post-comunismo, postbabyboom, post-capa de ozono. Aquí no hay realismo mágico; hay realismo virtual».

Los nuevos espacios de la creación literaria ya no están confinados en los estados-nación o en las naciones-estado, ni en el deseable subcontinente federalizado sońado por Bolívar, sino que se inscriben en los marcos imprecisos de la cultura pop, del ciberespacio, la blogosfera, la mentalidad abierta de las grandes migraciones.

La historia, como vemos, ya es otra. La literatura, en consecuencia, también. La ansiada voluntad integradora fomentada por Bolívar, primero, recuperada luego por Martí y más tarde con lo que supuso la Revolución Cubana de 1959, y los viejos nacionalismos literarios del siglo XIX de la América Latina, han sido desplazados por esta nueva manera de ver las cosas jalonada por las antologías y el manifiesto mencionados y por poéticas narrativas de autores que van por su cuenta y algunos de los cuales han sido analizados por el mismo Jorge Fornet en el trabajo aludido, entre ellos, el chileno Pedro Lemebel, el costarricense Carlos Cortés, el colombiano Héctor Abad Faciolince, autor de una novela, Basura (2000), una suerte de réplica inteligente al Gabriel García Márquez de Cien años de soledad, o el siempre inquietante, original y tristemente desaparecido Roberto Bolaño. El auge cobrado por la literatura femenina durante las últimas décadas merecería capítulo aparte.

La calidad literaria de estos escritores latinoamericanos del siglo Xxi está por calibrar en toda su dispersa dimensión, pero su concepción de la historia particular del subcontinente del que proceden y de la historia del mundo al que pertenecen, es muy distinta a la de los escritores que independizaron América en el siglo XIX de los fórceps del Imperio español.

Los siglos no han pasado en balde. Más que de la certeza, madre de todos los aniquilamientos creativos, como han propuesto los escritores del Crack, hoy esa literatura del siglo Xxi nace de la duda, hermana mayor del conocimiento.

Esa literatura se mueve, como nos ha aclarado Claudio Magris (2008: 33), con quien nos gustaría terminar, en esa era "posmoderna, global y sofisticada, que transforma tecnológicamente el mundo a ritmos vertiginosos, pero duda si podrá darle un sentido».

Recibido: agosto de 2012. Aceptado: octubre de 2012. 


\section{REFERENCIAS BIBLIOGRÁFICAS}

\section{A)Monografías}

Anderson, Benedict (1993): Comunidades imaginadas. Reflexiones sobre el origen y la difusión del nacionalismo, traducción de Eduardo L. Suárez, México, FCE, 4. ${ }^{a}$ reimp.

Berlin, Isaiah (2000): Vico y Herder. Dos estudios en la historia de las ideas, edición de Henry Hardy y traducción de Carmen González del Tejo, Madrid, Cátedra.

Bolaño, Roberto (1996): La literatura nazi en América, Barcelona, Seix Barral.

Bolívar, Simón (1981): Discursos, proclamas y epistolario político, edición preparada por M. Hernández Sánchez-Barba, Madrid, Editora Nacional, 3. ${ }^{\mathrm{a}}$ ed.

Folger, Robert y Leopold Stephan (eds.) (2010): Escribiendo la Independencia. Perspectivas postcoloniales sobre la literatura hispanoamericana del siglo XIX, Madrid, Iberoamericana Vervuert.

García Márquez, Gabriel (1989): El general en su laberinto, Madrid, Mondadori.

Magris, Claudio (2001): Utopias y desencanto. Historias, esperanzas e ilusiones de la modernidad, traducción de J. A. González Sainz, Barcelona, Círculo de Lectores.

_ (2008): «En el camino de don Quijote», en El infinito viajar, traducción de Pilar García Colmenarejo, Barcelona, Anagrama.

Manifiesto Crack (2000): Lateral. Revista de Cultura, México, núm. 70, octubre.

Menton, Seymour (1993): La nueva novela histórica de la América Latina, 1979-1992, México, Fondo de Cultura Económica.

PAz, Octavio (1986): «El cuerpo del delito», en Sombras de obras. Arte y literatura, Barcelona, Seix Barral, 2. ${ }^{\text {a }}$ ed.

\section{B) Partes o Capítulos de monografías}

Díaz-Caballero, J. (1997): «Ángel Rama y la crítica de la transculturación (Última entrevista)», en Moraña, Mabel (ed.), Ángel Rama y los estudios latinoamericanos, Universidad de Pittsburgh, IILI, pp. 325-348.

Oviedo, José Miguel (1997): «García Márquez en el laberinto de la soledad», en Quinientos años de soledad. Actas del Congreso Gabriel García Márquez, Universidad de Zaragoza, Colección Trópica, 3, Anexos de Tropelías, p. 73. 
C) Artículos en publicaciones en SERIE

Echevarría, Ignacio (2010): «Rostros sin espejo», El Cultural, El Mundo, Madrid, 2-8 julio, p. 25.

ForNET, Jorge: «Y finalmente, ¿existe una literatura latinoamericana?», La Jiribilla. Revista de Cultura, La Habana, Año vi, sábado 9 de junio de 2007.

Fuentes, Carlos (2004): «Tres encuentros con el Rey Midas», El País, Madrid, 11 de julio, p. 6.

Rojo, Grínor (2008): Discursos/prácticas, Universidad de Chile, núm. 2, (Sem. 1), p. 95. 